\title{
EVALUASI VARIASI NILAI ELECTRICAL CONDUCTIVITY TERHADAP PERTUMBUHAN TANAMAN SELADA (Lactuca sativa L.) PADA SISTEM NFT
}

\section{EVALUATION OF VARIATION ELECTRICAL CONDUCTIVITY VALUE ON THE GROWTH OF LETTUCE (Lactuca sativa L.) IN THE NFT SYSTEM}

\author{
Budy Frasetya, Ahmad Taofik, Riki K. Firdaus \\ Jurusan Agroteknologi, Fakultas Sains dan Teknologi, UIN Sunan Gunung Djati \\ Jl. AH. Nasution No. 105 Cibiru Bandung \\ Korespondensi : budyftq1682@gmail.com
}

Diterima 7 Agustus 2018 / Disetujui 23 November 2018

\begin{abstract}
ABSTRAK
Tanaman selada di Indonesia umumnya dikonsumsi dalam bentuk segar. Evaluasi pengaturan nilai Electrical Conductivity (EC) sesuai umur tanaman selada diperlukan sebagai upaya menjaga kualitas produk (berat segar, tampilan visual) dan meningkatkan efisiensi penggunaan nutrisi. Penelitian ini dilakasanakan pada September-Oktober 2017 bertempat di Kecamatan Banjaran. Percobaan yang dilakukan menggunakan Rancangan Acak Lengkap terdiri dari 4 taraf dan diulang 6 kali. Perlakuan yang diberikan merupakan kombinasi nilai EC fase vegetatif awal $\left(V_{1}\right)$ dan fase vegetatif akhir $\left(V_{I I}\right)$ perlakuan $A=\left(V_{1}=1,5 ; V_{I I}=2,0\right) ; B=\left(V_{1}=1,6 ; V_{I I}=\right.$ $2,2) ; C=\left(V_{1}=1,7 ; V_{\|}=2,4\right) ; D=\left(V_{1}=1,8 ; V_{\|}=2,6\right) \mathrm{mS} \mathrm{cm}^{-1}$. Aplikasi nilai $E C\left(V_{1}=1,7 ; V_{\|}=2,4\right) \mathrm{mS}$ $\mathrm{cm}^{-1}$ memberikan pertumbuhan tertinggi (tinggi tanaman, luas daun, bobot segar tanaman). Berdasarkan hasil berat segar tanaman pengaturan nilai EC dapat meningkatkan efisiensi penggunaan nutrisi hidroponik.
\end{abstract}

Kata kunci: Cekaman abiotik, efisiensi nutrisi, kualitas air

\begin{abstract}
Lettuce is commonly consuming as a fresh vegetable in Indonesia. The evaluation of electrical conductivity adjustment by lettuce plant age is an effort to achieve quality product (fresh weight, visual appearance) and improve nutrient efficiency. This research conducted in September-October 2017 at Banjaran District. This experiment used a completely randomized design with 4 level treatments and replicated six times. Application of combination EC value phase vegetative $I$ and vegetative $I I$, respectively: $A=\left(V_{1}=1.5 ; V_{\|}=2.0\right) ; B=\left(V_{1}=1.6 ; V_{\|}=\right.$ 2.2); $C=\left(V_{1}=1.7 ; V_{\| I}=2.4\right) ; D=\left(V_{1}=1.8 ; V_{\|}=2.6\right) \mathrm{mS} \mathrm{cm}^{-1}$. This research showed that application nutrient with $E C$ value $\left(V_{I}=1.7 ; V_{I I}=2.4\right) \mathrm{mS} \mathrm{cm}^{-1}$ affect plant growth higher (plant height, leaf area, fresh weight). Based on the results of the plant's fresh weight parameter EC value improved the efficiency of using hydroponic nutrient.
\end{abstract}

Keywords: Abiotic stress, nutrient efficiency, water quality

ISSN : 2407-7933

Cite this as: Frasetya, B. Taofik, A. \& Firdaus, R. K. (2018). Evaluasi variasi nilai electrical conductivity terhadap pertumbuhan tanaman selada (Lactuca sativa L.) pada sistem hidroponik NFT. Jurnal Agro, 5(2), 95-102. https://doi.org/10.15575/2966 


\section{PENDAHULUAN}

Pembangunan infrastruktur kota dan pemukiman tidak semuanya tertutup oleh bangunan. Lahan kosong antar bangunan dapat dimanfaatkan untuk menanam beragam jenis sayuran. Konsep pemanfaatan lahan di perkotaan untuk pertanian dikenal dengan istilah urban farming atau urban agriculture (Wortman \& Lovell, 2014).

Tanaman selada merupakan salah satu tanaman sayuran yang dapat dibudidayakan sebagai komoditas sayuran urban farming. Potensi pasar terbesar tanaman selada umumnya berada di perkotaan dan dikonsumsi langsung dalam bentuk sayuran segar. Upaya memperpendek jalur distribusi hasil panen tanaman selada dari produsen ke konsumen diharapkan tanaman selada yang dihasilkan dapat lebih cepat sampai ke konsumen sehingga terjaga kesegarannya.

Penerapan teknologi hidroponik sudah diketahui secara luas sebagai sistem budidaya tanaman di perkotaan yang memiliki keunggulan produktivitas tinggi pada jarak tanam rapat, bebas pestisida dan menghasilkan tanaman dengan daya tahan kesegaran lebih lama (Domingues et al., 2012; Maboko et al., 2009; Sutiyoso, 2006).

Kendala penerapan teknologi hidroponik di masyarakat diantaranya ketersediaan nutrisi yang masih terbatas distribusinya dan harga nutrisi tanaman yang relatif mahal (Frasetya et al., 2018).

Pada penelitian ini sistem hidroponik yang digunakan adalah sistem Nutrient Film Technique (NFT), kontak aliran nutrisi dengan perakaran tanaman $\pm 3 \mathrm{~mm}$ di awal pertumbuhan. Keunggulan sistem NFT dari aspek teknis adalah dapat disusun bertingkat dengan pemilihan bahan tiang penyangga yang lebih sederhana, dikarenakan beban air nutrisi, tanaman dan pipa atau talang air dalam setiap tingkat instalasi lebih ringan bila dibandingkan dengan sistem Deep Flow Technique (DFT), sistem rakit apung, sistem sumbu, dan sistem pasang surut.

Sistem NFT ditinjau dari aspek ekonomis menghasilkan produksi lebih tinggi. Hasil penelitian Wibowo \& Asriyanti (2013) menunjukkan bahwa tanaman Pakcoy yang ditanam pada sistem NFT menghasilkan panen lebih tinggi. Hasil tanaman selada berkualitas tidak hanya ditentukan oleh pemilihan sistem hidroponik yang tepat namun perlu diimbangi pula dengan pemberian nutrisi yang tepat.

Nilai Electrical Conductivity (EC) dan $\mathrm{pH}$ nutrisi umum digunakan sebagai indikator untuk menghasilkan hasil panen berkualitas (Hidayat et al., 2018). Pengaturan nilai EC selain dapat meningkatkan pertumbuhan tanaman juga merupakan salah satu upaya untuk menghemat kebutuhan nutrisi hidroponik.

Nilai EC merupakan indikator kepekatan nutrisi, semakin tinggi nilai EC maka nutrisi yang diberikan pada tanaman semakin banyak sehingga kebutuhan larutan stok semakin banyak. Hasil penelitian Pratiwi et al. (2015) aplikasi EC (mS cm$~^{-1}$ ) 1,5 dan 2 pada larutan nutrisi menghasilkan bobot segar yang sama pada tanaman sawi sedangkan pemberian EC 2,5 memberikan bobot segar tertinggi pada sistem aeroponik. Variasi nilai EC pada tanaman hidroponik dipengaruhi oleh varietas, umur, $\mathrm{pH}$ dan sistem hidroponik yang digunakan (Hashida et al., 2014; Utomo et al., 2014; Wibowo \& Asriyanti, 2013). Berdasarkan pertimbangan tersebut aplikasi variasi nilai EC dapat meningkatkan pertumbuhan tanaman selada. 
Penelitian ini bertujuan untuk memperoleh nilai EC optimum dalam mendukung pertumbuhan tanaman selada berkualitas pada sistem NFT, sekaligus efisiensi penggunaan unsur hara. Selain itu penelitian ini dilakukan untuk mendapatkan efisiensi unsur hara.

\section{BAHAN DAN METODE}

Percobaan telah dilaksanakanan pada bulan September-Oktober 2017 di Kecamatan Banjaran Kabupaten Bandung (718 m dpl). Bahan dan alat yang digunakan pada penelitian ini, yaitu: benih selada, hidrogel, pupuk $A B$ Mix, bahan instalasi NFT, EC meter, pH meter, termohigrometer, timbangan, pompa air.

Rancangan percobaan yang digunakan adalah Rancangan Acak Lengkap (RAL) terdiri dari 4 perlakuan $\left(A=E C\left(V_{1}=1,5 \mathrm{mS}\right.\right.$ $\left.\mathrm{cm}^{-1}, \mathrm{~V}_{\mathrm{II}}=2,0 \mathrm{mS} \mathrm{cm}{ }^{-1}\right) ; B=E C\left(\mathrm{~V}_{1}=1,6 \mathrm{mS}\right.$ $\left.\mathrm{cm}^{-1}, \mathrm{~V}_{\mathrm{II}}=2,2 \mathrm{mS} \mathrm{cm}^{-1}\right) ; \mathrm{C}=\mathrm{EC}\left(\mathrm{V}_{\mathrm{I}}=1,7 \mathrm{mS}\right.$ $\left.\mathrm{cm}^{-1}, \mathrm{~V}_{\|}=2,4 \mathrm{mS} \mathrm{cm}^{-1}\right) ;$ dan $\mathrm{D}=\mathrm{EC}\left(\mathrm{V}_{\mathrm{l}}=1,8\right.$ $\left.\mathrm{mS} \mathrm{cm}{ }^{-1}, \mathrm{~V}_{\mathrm{II}}=2,6 \mathrm{mS} \mathrm{cm}^{-1}\right)$ ). Masing-masing perlakuan diulang sebanyak enam kali. Aplikasi nilai EC pada setiap perlakuan vegetatif I $\left(V_{1}\right)$ diberikan pada saat tanaman berumur 1-14 hari setelah tanam (HST) dan aplikasi nilai EC vegetatif II $\left(\mathrm{V}_{\mathrm{II}}\right)$ diberikan pada saat tanaman berumur 15-35 HST.

Pengamatan yang dilakukan dalam penelitian ini meliputi pengamatan utama (tinggi tanaman, luas daun dan bobot segar) dan pengamatan penunjang $(\mathrm{pH}$, suhu udara, suhu larutan nutrisi).

Data hasil pengamatan pertumbuhan kemudian dianalisis menggunakan analisis varians $(\alpha=5 \%)$ dan apabila hasil uji $F$ taraf perlakuan berbeda nyata dilanjutkan dengan uji beda jarak berganda (Duncan Multiple Range Test) ( $\alpha=5 \%)$. Data hasil pengamatan penunjang dianalisis menggunakan analisis regresi untuk mempertajam analisis pengamatan utama. Tahapan kegiatan penelitian, yaitu persemaian, pembuatan instalasi NFT, pembuatan larutan stok nutrisi, pindah tanam, pemeliharaan dan panen.

\section{HASIL DAN PEMBAHASAN}

\section{Suhu Green House dan Suhu Larutan}

Rata-rata suhu harian selama penelitian $30,14{ }^{\circ} \mathrm{C}$ dan suhu larutan $27,46{ }^{\circ} \mathrm{C}$. Fluktuasi Suhu larutan nutrisi relatif lebih kecil bila dibandingkan dengan suhu ruangan. Suhu larutan nutrisi perlu dijaga agar fluktuasi suhunya rendah tujuannya untuk mencegah tanaman dari cekaman akibat fluktuasi nilai EC, pH (Domingues et al., 2012) dan Disolve Oxygen (DO) (Suyantohadi et al., 2010). Cekaman abiotik dapat mengakibatkan penurunan produksi.

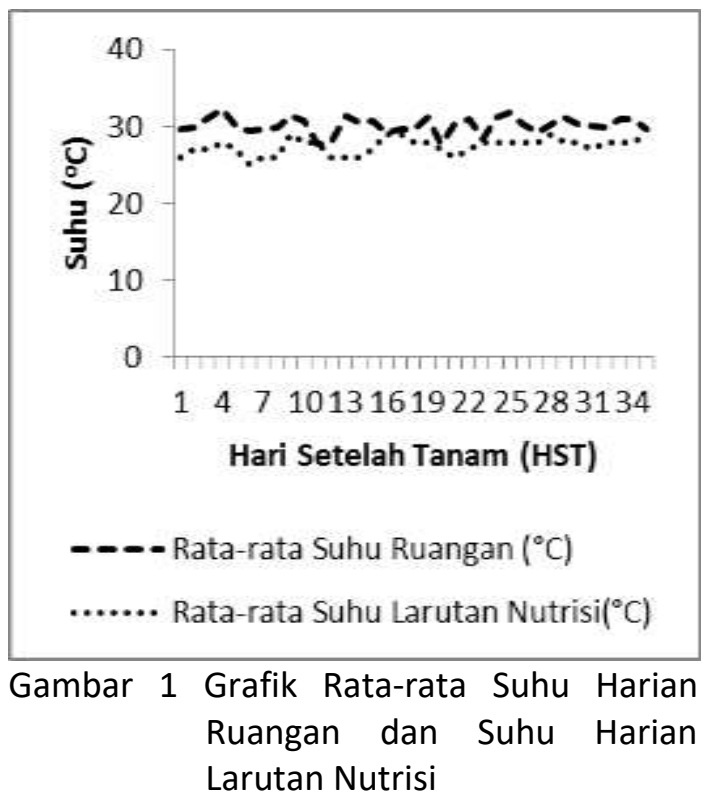

Pada penelitian ini suhu larutan nutrisi cukup tinggi. Menurut Gruda (2005) pertumbuhan tanaman selada mencapai pertumbuhan terbaik apabila suhu larutan nutrisi berkisar $24^{\circ} \mathrm{C}$ meskipun suhu udara ruangan mencapai $31^{\circ} \mathrm{C}$ (Gambar 1). 
Penyimpanan nutrisi dalam bak nutrisi yang kedap cahaya (berbahan plastik) belum mampu menjaga suhu nutrisi dibawah $25^{\circ} \mathrm{C}$.

\section{Nilai pH Larutan Nutrisi}

Terdapat variasi $\mathrm{pH}$ larutan pada perlakuan $\mathrm{A}$, adapun $\mathrm{pH}$ nutrisi selama penelitian berlangsung 6,37. Pada fase vegetatif I (1-14 HST) dengan EC $1,5 \mathrm{mS} \mathrm{cm}^{-1}$ dan fase vegetatif II dengan EC $2,0 \mathrm{mS} \mathrm{cm}^{-1}$, terjadi peningkatan $\mathrm{pH}$ pada awal pindah tanam. Hal ini disebabkan tanaman lebih banyak menyerap nutrisi yang bermuatan negatif $\left(\mathrm{NO}_{3}{ }^{-}\right)$, sebaliknya pada fase vegetatif II terjadi penurunan nilai $\mathrm{pH}$ sebagai indikator tanaman lebih banyak menyerap unsur hara bermuatan positif $\left(\mathrm{NH}_{4}{ }^{+}\right)$. Fluktuasi rasio $\mathrm{NO}_{3}{ }^{-}$terhadap $\mathrm{NH}_{4}{ }^{+}$ pada larutan nutrisi berpengaruh terhadap perubahan $\mathrm{pH}$ seiring dengan pertambahan umur tanaman (Islam et al., 2009).

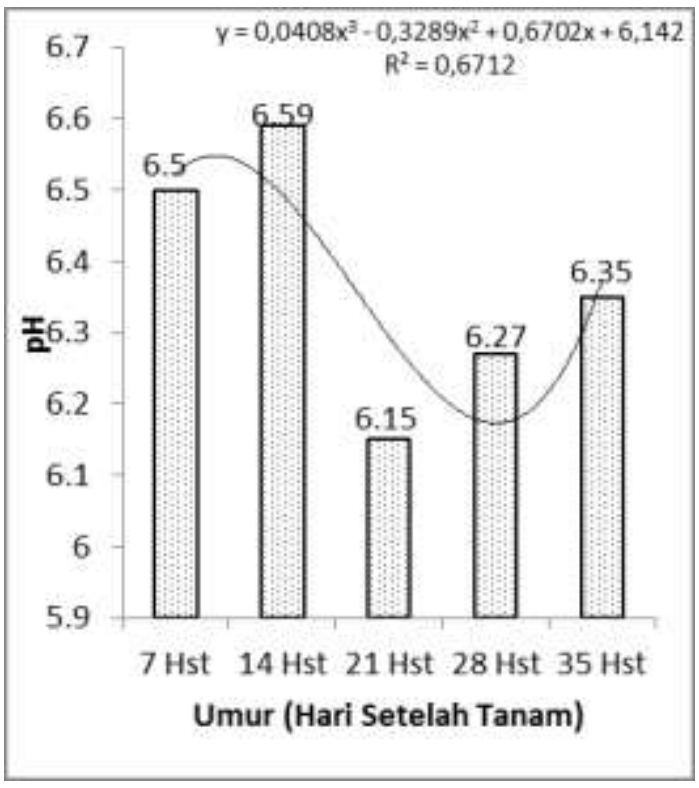

Gambar 2 Grafik Perubahan pH terhadap Umur Tanaman

Berdasarkan uji Koefisien korelasi persamaan regresi polinomial orde 3 diperoleh nilai $r=0,819$ (Gambar 2). Menurut Sugiyono (2012) nilai korelasi tersebut memiliki hubungan sangat kuat, artinya perubahan nilai $\mathrm{pH}$ dipengaruhi oleh umur tanaman.

\section{Tinggi Tanaman $(\mathrm{cm})$}

Hasil analisis data tinggi tanaman (7, 21 dan 35 HST) menunjukkan bahwa variasi nilai EC berpengaruh terhadap tinggi tanaman selada (Gambar 3). Tinggi tanaman pada semua taraf perlakuan pada penelitian ini lebih rendah dibandingkan dengan hasil penelitian Zuhaida et al. ( 2012) yaitu 59,24 $\mathrm{cm}$ pada umur $28 \mathrm{HST}$, namun respons tinggi tanaman pada penelitian ini lebih tinggi dibandingkan dengan hasil penelitian Wulandari et al. (2017) tinggi tanaman selada yang dihasilkan $21,82 \mathrm{~cm}$ pada 35 HST.

Tinggi tanaman dipengaruhi perubahan lingkungan seperti cahaya dan air (Sitompul, 2016). Tanaman yang kekurangan cahaya dapat menunjukkan gejala tinggi berlebihan dibandingkan dengan tanaman yang memperoleh cahaya yang cukup. Variasi tinggi tanaman pada setiap taraf perlakuan memberikan informasi bahwa aplikasi EC vegetatif । 1,5 dan $1,6 \mathrm{mS} \mathrm{cm}^{-1}$ dan EC vegetatif II 2,0 dan $2,2 \mathrm{mS} \mathrm{cm}^{-1}$ sudah memberikan pengaruh terhadap parameter tinggi tanaman (perlakuan A dan B) sedangkan aplikasi EC vegetatif I 1,7 dan 1,8 $\mathrm{mS} \mathrm{cm}{ }^{-1}$ dan EC vegetatif II 2,4 dan 2,6 mS $\mathrm{cm}^{-1}$ cenderung menghasilkan pertumbuhan tinggi tanaman yang relatif sama dengan perlakuan A dan B (aplikasi EC lebih rendah).

\section{Luas Daun $\left(\mathrm{cm}^{2}\right)$}

Variasi nilai EC pada setiap taraf perlakuan berpengaruh terhadap luas daun tanaman selada. Luas daun tertinggi diperoleh pada perlakuan $\mathrm{C}\left(\mathrm{V}_{\mathrm{l}}=1,7 \mathrm{mS} \mathrm{cm}\right.$ ${ }^{1} ; \mathrm{V}_{\mathrm{II}}=2,4 \mathrm{mS} \mathrm{cm}^{-1}$ ). Hasil analisis regresi 
polinomial orde $3 \quad(r=1)$ menguatkan variasi nilai EC (Gambar 4).

informasi bahwa luas daun dipengaruhi oleh

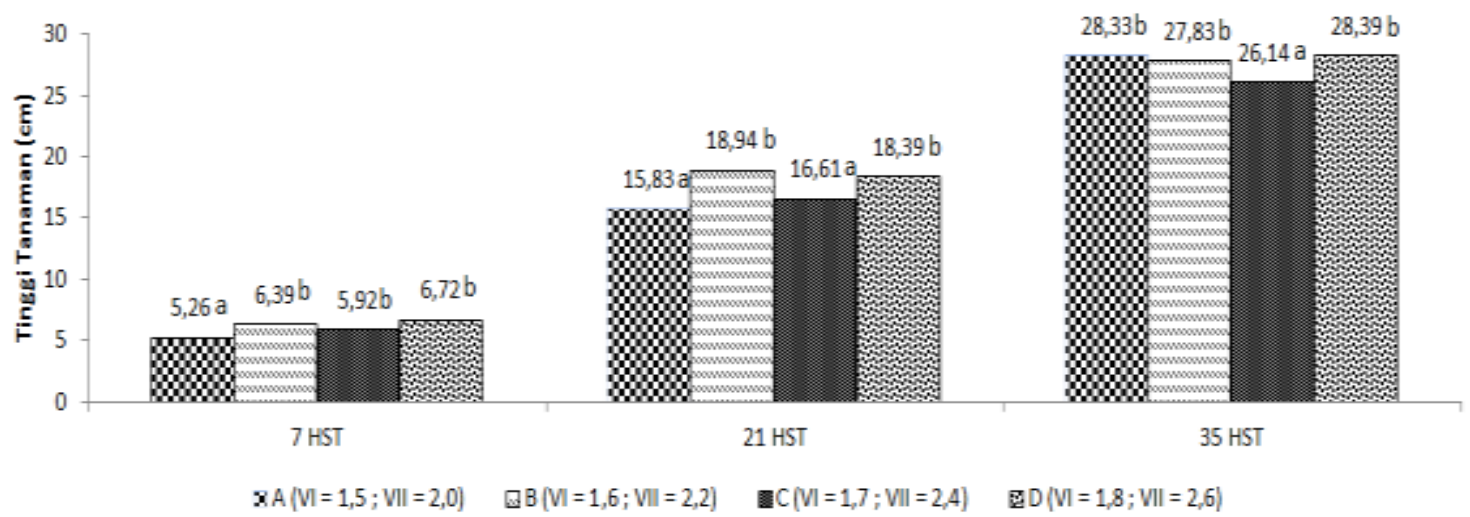

Gambar 3 Grafik Tinggi Tanaman (cm) pada Umur Tanaman 7, 21 dan 35 HST

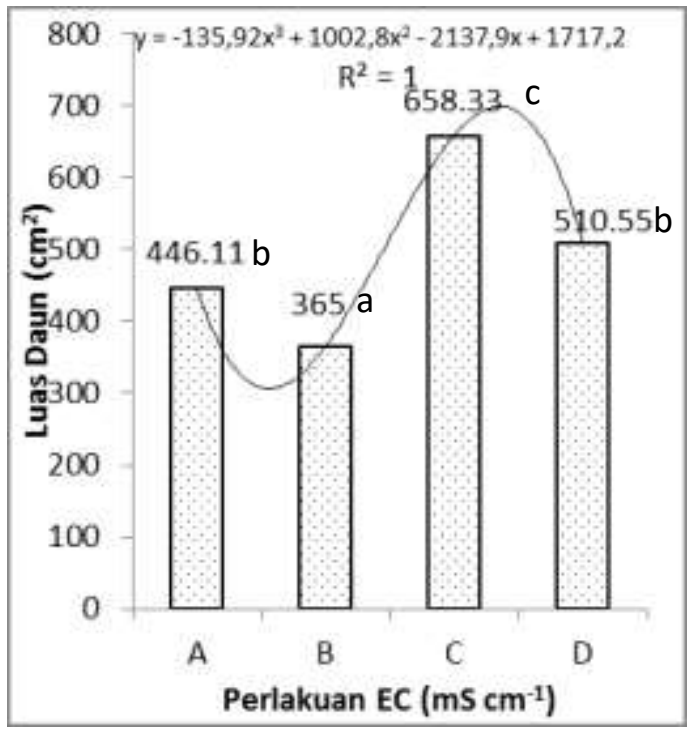

Keterangan: $A=E C\left(V_{1}=1,5 \mathrm{mS} \mathrm{cm}^{-1}, V_{\| I}=2,0 \mathrm{mS}\right.$ $\left.\mathrm{cm}^{-1}\right) ; \mathrm{B}=\mathrm{EC}\left(\mathrm{V}_{\mathrm{l}}=1,6 \mathrm{mS} \mathrm{cm} \mathrm{cm}^{-1}, \mathrm{~V}_{\|}=\right.$ $\left.2,2 \mathrm{mS} \mathrm{cm}^{-1}\right) ; C=E C\left(V_{1}=1,7 \mathrm{mS} \mathrm{cm}^{-}\right.$ $\left.{ }^{1}, \mathrm{~V}_{\mathrm{II}}=2,4 \mathrm{mS} \mathrm{cm}^{-1}\right)$; dan $\mathrm{D}=\mathrm{EC}\left(\mathrm{V}_{\mathrm{I}}=\right.$ $1,8 \mathrm{mS} \mathrm{cm}^{-1}, \mathrm{~V}_{\|}=2,6 \mathrm{mS} \mathrm{cm}^{-1}$ )

Gambar 4 Grafik Luas Daun Terhadap Taraf Perlakuan Nilai EC

Berdasarkan grafik regresi polinomial luas daun optimum diperoleh pada variasi nilai EC diantara taraf perlakuan $C$ dan $D$. Pemberian EC lebih dari $2,6 \mathrm{mS} \mathrm{cm}^{-1}$ pada parameter luas daun menghasilkan luas daun lebih sempit. Efisiensi pemberian unsur hara dicapai pada EC 2,4-2,6 $\mathrm{mS} \mathrm{cm}^{-1}$.
Intesitas cahaya dan pengaturan nilai EC mempengaruhi hasil dan kualitas tanaman selada (Stagnari et al., 2015).

Luas daun berkaitan dengan kemampuan tanaman untuk melakukan fotosintesis. Tanaman yang memiliki luas daun lebih besar akan menghasilkan pertumbuhan optimum (Sinaga et al., 2014)

\section{Berat Segar Tanaman (g)}

Hasil uji jarak berganda Duncan rata-rata berat segar tanaman (Gambar 5) menunjukkan bahwa taraf perlakuan $\mathrm{C}$ menghasilkan berat segar tanaman paling tinggi dibandingkan taraf perlakuan lainnya. Nilai EC perlakuan $C$ lebih tinggi $\pm 13 \%$ dari perlakuan EC terendah (A) namun menghasilkan $\pm 36 \%$ berat segar tanaman lebih tinggi. Efisiensi penggunaan unsur hara perlakuan $\mathrm{C}$ terhadap hasil panen sebesar $\pm 23 \%$.

Hasil analisis regresi polinomial orde 3 menunjukkan koefisien regresi $(r=1)$ menurut Sugiyono (2012) nilai $r=1$ menunjukkan bahwa Nilai EC memiliki hubungan sangat kuat terhadap peningkatan berat segar tanaman. Bobot segar yang dihasilkan pada penelitian ini 
(79,32 g) lebih rendah dari hasil penelitian Zuhaida et al. (2012) (126,94 g) pada perlakuan pemberian $\mathrm{Fe} \quad 6 \quad \mathrm{ppm}$. Ketersediaan unsur hara pada setiap fase pertumbuhan dapat meningkatkan bobot segar tanaman (Embarsari et al., 2015).

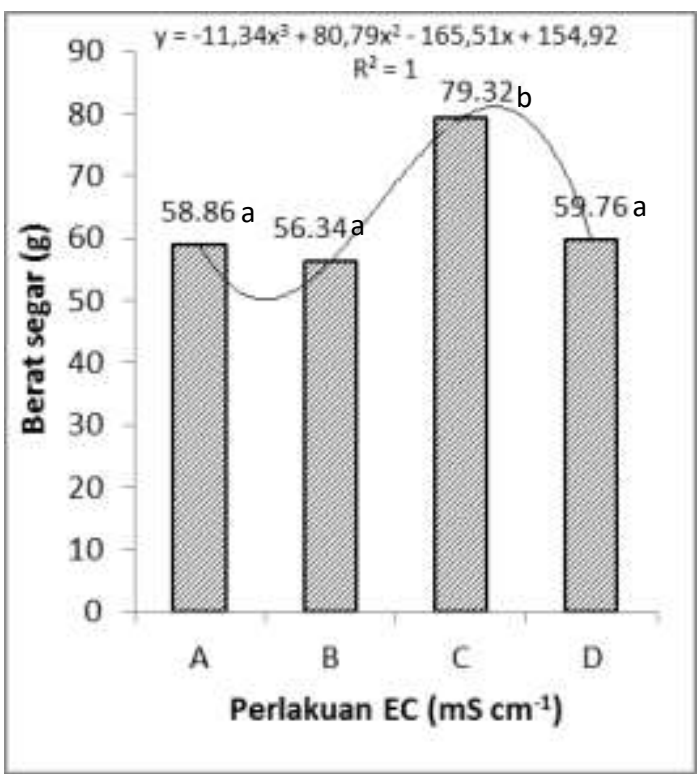

Keterangan: $A=E C\left(V_{1}=1,5 \mathrm{mS} \mathrm{cm}^{-1}, V_{\|}=2,0 \mathrm{mS}\right.$ $\left.\mathrm{cm}^{-1}\right) ; \mathrm{B}=\mathrm{EC}\left(\mathrm{V}_{\mathrm{l}}=1,6 \mathrm{mS} \mathrm{cm}^{-1}, \mathrm{~V}_{\|}=\right.$ $\left.2,2 \mathrm{mS} \mathrm{cm}^{-1}\right) ; C=E C\left(V_{1}=1,7 \mathrm{mS} \mathrm{cm}^{-}\right.$ $\left.{ }^{1}, \mathrm{~V}_{\mathrm{II}}=2,4 \mathrm{mS} \mathrm{cm}^{-1}\right) ;$ dan $\mathrm{D}=\mathrm{EC}\left(\mathrm{V}_{\mathrm{I}}=\right.$ $1,8 \mathrm{mS} \mathrm{cm}^{-1}, \mathrm{~V}_{\text {II }}=2,6 \mathrm{mS} \mathrm{cm}^{-1}$ )

Gambar 5 Grafik Berat Segar Terhadap Taraf Perlakuan Nilai EC

Menurut $\mathrm{Fu}$ et al. (2017) intensitas matahari yang tinggi dikombinasikan dengan pemberian konsentrasi nutrisi rendah nitrogen (Nilai EC rendah) akan meningkatkan hasil tanaman selada. Penggunaan plastik UV sebagai atap rumah plastik (tempat penanaman) dengan shadding $14 \%$ (pengurangan instensitas.

\section{SIMPULAN}

1. Pengaturan aplikasi nilai EC pada setiap fase pertumbuhan meningkatkan pertumbuhan tanaman selada.

2. Aplikasi nilai EC fase vegetatif $I 1,7 \mathrm{mS}$ $\mathrm{cm}^{-1}$ dan fase vegetatif $\| 2,4 \mathrm{mS} \mathrm{cm}^{-1}$ dapat meningkatkan hasil panen 33\% lebih tinggi dibandingkan dengan pemberian EC lebih tinggi.

3. Berdasarkan hasil berat segar tanaman pengaturan nilai EC dapat meningkatkan efisiensi penggunaan nutrisi hidroponik.

\section{UCAPAN TERIMAKASIH}

Penulis mengucapkan terima kasih kepada Dekan Fakultas Sains dan Teknologi, Ketua Jurusan Agroteknologi UIN Sunan Gunung Djati, Dosen, Staf dan Laboran di lingkungan Jurusan Agroteknologi dan semua pihak yang telah membantu kelancaran penelitian ini.

\section{DAFTAR PUSTAKA}

Domingues, D. S., Takahashi, H. W., Camara, C. A. P., \& Nixdorf, S. L. (2012). Automated system developed to control pH and concentration of nutrient solution evaluated in hydroponic lettuce production. Computers and Electronics in Agriculture, 84, 53-61. https://doi.org/10.1016/j.compag.201 2.02.006

Embarsari, R. P., Taofik, A., \& Frasetya, B. (2015). Pertumbuhan dan hasil seledri (Apium Graveolens L.) pada sistem hidroponik sumbu dengan jenis sumbu dan media tanam berbeda. Jurnal Agro, 2(2), 41-48. https://doi.org/10.15575/437

Frasetya, B., Harisman, K., \& Rohim, A. (2018). Evaluasi nutrisi hidroponik alternatif terhadap pertumbuhan dan hasil mentimun Jepang varietas Roberto pada hidroponik irigasi tetes infus. In Prosiding Seminar Nasional Fakultas Pertanian UNS (Vol. 2, pp. 
230-238). Surakarta: Fakultas Pertanian Universitas Sebelas Maret.

Fu, Y., Li, H., Yu, J., Liu, H., Cao, Z., Manukovsky, N. S., \& Liu, H. (2017). Interaction effects of light intensity and nitrogen concentration on growth, photosynthetic characteristics and quality of lettuce (Lactuca sativa L. Var. youmaicai). Scientia Horticulturae, 214 51-57. https://doi.org/10.1016/j.scienta.2016 .11 .020

Gruda, N. (2005). Impact of environmental factors on product quality of greenhouse vegetables for fresh consumption. Critical Reviews in Plant Sciences, 24(3), 227-247. https://doi.org/10.1080/07352680591 008628

Hashida, S., Kitazaki, K., Shoji, K., Goto, F., \& Yoshihara, T. (2014). Influence of nitrogen limitation and long-term use of rockwool on nitrous oxide Emissions in hydroponic systems. Journal of Horticulture, 01(03), 2-7. https://doi.org/10.4172/23760354.1000113

Hidayat, C., Pahlevi, M. R., Frasetya, B., \& Ramdhani, M. A. (2018). Growth and yield of chili in nutrient film technique at different electrical conductivity. IOP Conference Series: Materials Science and Engineering, 288(1). https://doi.org/10.1088/1757899X/288/1/012034

Islam, S., Kazunori, K., Takeda, N., \& Ishikawa, K. (2009). High quality komatsuna (Brassica rapa L . nothovar) production by using silicate minerals treated nutrient solution sheheli islam, Kumagai Kazunori , Noriko Takeda and Katsumi Ishikawa Lab of Biological and Environmental Systems. American Journal of Agricultural and Biological Sciences,
4(1),12-17.

https://doi.org/10.3844/ajabssp.2009.

12.17

Maboko, M. M., Du Plooy, C. P., \& Bertling, I. (2009). Comparative performance of tomato cultivars in soilless vs. in-soil production systems. Acta Horticulturae, 843(October), 319-326. https://doi.org/10.17660/ActaHortic.2 009.843 .42

Pratiwi, P. R., Subandi, M., \& Mustari, E. (2015). Pengaruh tingkat EC (Electrical Conductivity) terhadap pertumbuhan tanaman sawi (Brassica juncea L.) pada sistem instalasi aeroponik vertikal. Jurnal Agro, II(1), 50-55. https://doi.org/10.15575/163

Sinaga, P., Meiriani, \& Hasanah, Y. (2014). Respons Pertumbuhan dan Produksi Kailan (Brassica oleraceae L.) pada pemberian berbagai dosis pupuk organik cair paitan (Tithonia diversifolia ( Hemsl .) Gray ). Jurnal Online Agroekoteknologi, 2(4), 15841588.

Sitompul, S. M. (2016). Analisis pertumbuhan tanaman. Malang: UB Press.

Stagnari, F., Galieni, A., \& Pisante, M. (2015). Shading and nitrogen management affect quality, safety and yield of greenhouse-grown leaf lettuce. Scientia Horticulturae, 192, 70-79.

https://doi.org/10.1016/j.scienta.2015 .05 .003

Sugiyono. (2012). Statistika untuk penelitian. Bandung: Alfabeta.

Sutiyoso, Y. (2006). Hidroponik ala Yos. Jakarta: Penebar Swadaya.

Suyantohadi, A., Kyoren, T., Hariadi, M., Purnomo, M. H., \& Morimoto, T. 
(2010). Effect of high consentrated dissolved oxygen on the plant growth in a deep hydroponic culture under a low temperature. IFAC Proceedings Volumes (IFAC-PapersOnline), 3(PART 1). https://doi.org/10.3182/201012063-JP-3009.00044

Utomo, W. Y., Bayu, E. S., \& Nuriadi, I. (2014). Keragaan beberapa varietas Pakchoi (Brassica rapa L. ssp. chinensis) pada dua jenis larutan hara dengan metode hidroponik terapung. Online Agroteknologi, 2(2337), 16611666. Retrieved from http://jurnal.usu.ac.id/index.php/agro ekoteknologi/article/view/8598/3730

Wibowo, S., \& Asriyanti, A. (2013). Aplikasi hidroponik NFT pada budidaya Pakcoy (Brassica rapa chinensis). Jurnal Penelitian Pertanian Terapan, 13(3), 159-167.

Wortman, S. E., \& Lovell, S. T. (2014). Environmental Challenges Threatening the Growth of Urban Agriculture in the United States. Journal of Environment
Quality, $\quad 42(5), \quad 1283$. https://doi.org/10.2134/jeq2013.01.0 031

Wulandari, S., Harjoko, D., \& Djoko, T. (2017). Pertumbuhan selada dalam hidroponik substrat dengan perbedaan ukuran serat aren dan nutrisi. In Peranan Sumber Daya Pertanian, Perkebunan, dan Peternakan dalam Mendukung Ketahanan Pangan Nasional (pp. 165-172). Surakarta: Fakultas Pertanian Universitas Sebelas Mare. Retrieved from http://jurnal.fp.uns.ac.id/index.php/se mnas/article/download/963/675

Zuhaida, L., Ambarwati, E., \& Sulistyaningsih, E. (2012). Pertunbuhan dan Hasil Selada (Lactuca sativa L.) Hidroponik diperkaya Fe. VEGETALIKA, 1(4). Retrieved from https://jurnal.ugm.ac.id/jbp/article/vi ew/1597/1413 